Original Research Paper

\title{
Alterations in Interleukin-1 $\beta$ and Interleukin-6 in Mice Inoculated Through the Oral Routes Using Graded Doses of P. Multocida Type b: 2 and its Lipopolysaccharide
}

\author{
${ }^{1}$ Omar Suwaidan Ali, ${ }^{1,4}$ Lawan Adamu, ${ }^{1,2}$ Faez Firdaus Jesse Abdullah, ${ }^{3}$ Yusuf Ilyasu, ${ }^{1,4}$ Yusuf Abba, \\ ${ }^{3}$ Hazilawati Binti Hamzah, ${ }^{3}$ Mohd-Azmi M.L., ${ }^{1,2}$ Abdul Wahid B. Haron and ${ }^{3}$ Mohd Zamri B. Saad \\ ${ }^{1}$ Department of Veterinary Clinical Studies, \\ ${ }^{2}$ Research Centre for Ruminant Disease, \\ ${ }^{3}$ Department of Veterinary Pathology and Microbiology \\ Faculty of Veterinary Medicine, Universiti Putra Malaysia, 43400 UPM Serdang, Selangor, Malaysia \\ ${ }^{4}$ Faculty of Veterinary Medicine, University of Maiduguri, PMB 1069, Borno State, Nigeria
}

\author{
Article history \\ Received: 01-09-2014 \\ Revised: 20-09-2014 \\ Accepted: 04-10-2014 \\ Corresponding Author: \\ Faez Firdaus Jesse Abdullah \\ Department of Veterinary \\ Clinical Studies, Faculty of \\ Veterinary Medicine, \\ Universiti Putra Malaysia, \\ 43400 UPM Serdang, Selangor, \\ Malaysia \\ Email: jesseariasamy@gmail.com
}

\begin{abstract}
The gram-negative bacterium Pasteurella multocida serotype B: 2 is an important veterinary and opportunistic human pathogen that causes deplorable welfare problems and colossal economic production losses in bovine and other animal species throughout the world. Pasteurella multocida type B: 2 and its LPS are associated with Haemorrhagic Septicaemia (HS) in mice as animal model. Sixty healthy Balb c mice were placed in twelve plastic cages each one containing five mice. The mice were divided into three major groups (A, B and C). Group $A$ is the control group $(n=10)$ and these were inoculated with $0.4 \mathrm{~mL}$ of PBS pH 7.4 orally. The treatment groups (B; $n=25$ and C; $n=25$ ) were inoculated with $P$. multocida type B: 2 and lipopolysaccharide respectively. The mice in group $\mathrm{B}$ and $\mathrm{C}$ were further divided into five subgroups. The subgroups were designated based on the graded doses as $\mathrm{B} 10^{1}, \mathrm{~B} 10^{3}, \mathrm{~B} 10^{5}, \mathrm{~B} 10^{7}$ and $\mathrm{B} 10^{9}$ for Pasteurella multocida and $\mathrm{C} 10^{1}$, $\mathrm{C} 10^{3}, \mathrm{C} 10^{5}, \mathrm{C} 10^{7}$ and $\mathrm{C} 10^{9}$ for LPS respectively. The mice were observed for $120 \mathrm{~h}$ post-inoculation. The concentration of IL-1 $\beta$ was significantly higher $(\mathrm{p}<0.001)$ in the B10 $10^{7}$ of P. multocida type B: 2 and C $10^{9}$ of LPS compared to the control group and the other treatment groups. The concentration of IL-6 was significantly higher $(p<0.001)$ in the B $10^{3}$ cfu of P. multocida type B: 2 and C $10^{9}$ cfu of LPS compared to the control group and the other treatment groups. Interleukin-1 $\beta$ and interleukin- 6 evaluated in this study were predominantly associated with HS in varying doses of $10^{1}, 10^{3}, 10^{5}, 10^{7}$ and $10^{9}$ in the whole cell and its LPS respectively. Therefore, the target of this study was to investigate on proinflammatory response in mice infected with graded doses of Pasteurella multocida serotype B: 2 and its LPS via the oral route of inoculation.
\end{abstract}

Keywords: Lipopolysaccharides, Pasteurella Multocida Type B2, Cytokines, Oral Route, Graded Doses, Mice

\section{Intoduction}

Pasteurella multocida sero type B: 2 is a Gramnegative capsulated, cocco-bacillus which causes numerous deplorable diseases in a wild, domestic animals and humans (Jesse et al., 2013a). The organism is the etiological agent of Haemorrhagic septicaemia in cattle and water buffalo and it is predominant in South and South East Asia and to most parts of tropical Africa (Abubakar and Zamri-Saad, 2011; Kharb and Charan, 2013; Khaleel et al., 2013; Abdullah et al., 2013a; 2013b; Jesse et al., 2013a; 2013b). HS is a peracute disease and 
is considered to be one of the most economically important diseases in Asia particularly in South and South East Asia leading to huge economic loss in livestock industry (Jesse et al., 2013a). Cattle and buffalo are the usual host of HS (Jesse et al., 2013a; 2013b). Pasteurella multocida type B: 2 assumed to be transmitted between the animals by aerosol infection and ingestion of contaminated river water or material with $P$. multocida type B: 2 especially during the HS outbreak (Shafarin et al., 2009; Ataei et al., 2009; Khaleel et al., 2013). The clinical indication of this disease is often characterised by rapid course, high fever, loud and stertorous breathing, profuse salivation, severe depression and followed by death generally within a day of infection (Boyce et al., 2010; Jesse et al., 2013b).

Pathogenesis of $P$. multocida is a complex interaction between host specific factors and specific bacterial virulence factors; therefore, understanding the disease pathogenesis is complex and depends on the bacterial strain, the animal model and their interactions (Hawari et al., 2014). There are several disease models of infection with $P$. multocida using mice and show the suitability of mice to study the pathogenesis of $P$. multocida to produce HS with same symptoms and lesion in cattle and water buffalo (Affandi et al., 2012; Jamal et al., 2013; Faez et al., 2013). In pure chemical form endotoxin is a Lipopolysaccharide (LPS) which has widely variable composition (or chemotype) and exerts a wide range of often opposing influences on host pathogen interactions (Khaleel et al., 2013; Kharb et al., 2013). The key virulence factors identified in Pasteurella multocida type B: 2 include capsule, lipopolysaccharides, surface adhesions, ironregulated and iron acquisition proteins (Affandi et al., 2012; Kharb et al., 2013). The protein toxin from Pasteurella multocidatype B: 2 experimentally induce all of the major symptoms of a number of economically important diseases in domestic livestock (Jamal et al., 2013; Ataei et al., 2009; Faez et al., 2013). However, Pasteurella multocida is nonetheless an effective immunogen and mutant derivatives which showed potential for vaccine development (Ataei et al., 2009). Despite continuing investigations for several decades, the bacterial components LPS have been reported as virulence factor responsible for immuno-pathological changes (Jesse et al., 2013a; 2013b; 2013c). LPS is an integral component of the outer membrane of most gramnegative bacteria which is essential for cell survival and the humoral immune response to LPS varies and is dependent upon the host animal and on variations within the LPS structure (Moffatt et al., 2010).

Cytokines are a diverse group of small proteins ( $<200$ amino acids) that are secreted by a wide range of cell types for the purpose of intercellular signalling and communication. About 30 cytokines are recognized, Including the Interleukins (IL-1 $\beta$ and IL6) (Dionissopoulos et al., 2012). Among the many functions of cytokines are the control of cell proliferation and differentiation and the regulation of angiogenesis and immune and inflammatory responses (Dionissopoulos et al., 2012). IL-1 $\beta$ is a potent proinflammatory cytokine produced by a variety of cell types such as white blood cells (monocytes, macrophages and neutrophils) and endothelium has been documented (Monisha and Saxena, 2012; Rania et al., 2014). The principal effects of IL-1 $\beta$ are: Acute-phase response, phagocyte activation, Inflammation, Haematopoiesis and fever. Under immune stimulation, IL-1 $\beta$ also helps leukocytes pass through blood vessel walls to the site of infection and leads to fever by affecting areas of the brain that control body temperature (Dinarello, 2009; Monisha and Saxena, 2012; Rania et al., 2014). Interleukin-6 (IL-6) is a multifunctional cytokine and produced by a variety of cell types in both tissues of immune and endocrine systems (Dionissopoulos et al., 2012). It is extensively involved in promoting immune and haematopoietic bioactivities, such as interleukin gene expression, cell proliferation, B cell differentiation, $\mathrm{T}$ cell activation and neutrophil and macrophage differentiation (Gyenai et al., 2012).

There are predominant alterations in cytokines particularly IL-1 $\beta$ and IL-6 during a graded dose inoculation of mice with P. multocida serotype B: 2 and its LPS in the present study. To understand the pathogenesis of pasteurellosis, it is essential to investigate the profiles of host factors such as proinflammatory cytokines that are produced in relation to the alterations in cytokines with graded doses of $P$. multocida serotype B: 2 and its LPS. There are limited data in the literature on IL-1 $\beta$ and IL-6 alterations as a result of inoculation of mice with graded doses of $P$. multocida serotype B: 2 and its LPS via the oral route. Therefore, the present study, reported the proinflammatory cytokine profiles of mice experimentally infected orally with varying doses of $P$. multocida serotype B: 2 and its LPS.

\section{Materials and Methods}

\section{Animals}

Sixty healthy Balb c mice of eight to ten weeks old of both sexes were enrolled in this study. They were obtained from the Institute of Cancer Research (ICR) and kept at the Animal Resource Centre, Universiti Putra Malaysia. The animals were confirmed negative for $P$. multocida following culture of peripheral blood for bacterial isolations; the mice were housed in plastic 
cages and provided with water and pellet ad libitum. Five mice were kept in each plastic cage. The mice were observed for 2 weeks prior to the experiment to make sure that they were healthy and acclimatized.

\section{Inoculums}

Throughout the experiments, two types of inoculums were used; the whole cell and Lipopolysaccharide (LPS) extracted from $P$. multocida type B: 2 .

\section{Wild Type of P. Multocida Serotype B: 2}

The wild-type $P$. multocida type B: 2 used in this study were obtained from stock culture. It was isolated from a previous outbreak of Hemorrhagic Septicemia (HS) in the state of Kelantan, Malaysia. Identification of P. multocida was made using the Gram-staining method and biochemical characterization of oxidase, urea broth and Sulphur Indole Motility (SIM), Triple Sugar Iron (TSI) and citrate tests. The isolate was confirmed to be P. multocida type B: 2 by the Veterinary Research Institute (VRI) Ipoh, Perak. Pure stock culture that was stored on nutrient agar slants was sub-cultured onto $5 \%$ horse blood agar and incubated at $37^{\circ} \mathrm{C}$ for $18 \mathrm{~h}$. A single colony of $P$. multocida was selected and grown in Brain Heart Infusion broth (BHI), incubated in shaker incubator at $37^{\circ} \mathrm{C}$ for $24 \mathrm{~h}$ before the concentration was determined by McFarland Nephelometer Barium Sulfate Standards.

\section{The Lipopolysaccharide (LPS) P. Multocida B: 2}

The LPS Extraction Kit (Intron Biotechnology) was used to prepare the inoculums of LPS. For this experiment, LPS was extracted from different dosage of bacteria $\left(10^{1}, 10^{3}, 10^{5}, 10^{7}\right.$ and $\left.10^{9}\right) \mathrm{cfu}$. The whole cells were centrifuged for approximately $30 \mathrm{sec}$ at 13,000 rpm at room temperature. Then the supernatant was removed before $1 \mathrm{~mL}$ of lysed buffer was added and vortexed vigorously to lyse the bacterial cells. This was followed by adding $200 \mu \mathrm{L}$ of chloroform and vortexed vigorously. The mixture was incubated for $5 \mathrm{~min}$ at room temperature before centrifuged at $13,000 \mathrm{rpm}$ for $10 \mathrm{~min}$ at $4^{\circ} \mathrm{C}$. Then, $400 \mu \mathrm{L}$ of the supernatant was transferred into a new $1.5 \mathrm{~mL}$ centrifuge tube and $800 \mu \mathrm{L}$ of purification buffer was added. The mixture was incubated for $10 \mathrm{~min}$ at $-20^{\circ} \mathrm{C}$. This was followed by another centrifugation at $13,000 \mathrm{rpm}$ for $15 \mathrm{~min}$ at $4^{\circ} \mathrm{C}$. Lastly, the LPS pellet was washed with $1 \mathrm{~mL}$ of $70 \%$ ethanol and dried completely. Following that, $70 \mu \mathrm{L}$ of $10 \mathrm{mM}$ Tris- $\mathrm{HCl}\left(\mathrm{pH} \mathrm{8.0)}\right.$ (Sigma $\left.{ }^{\circledR}\right)$ was added into the LPS pellet and was dissolved by boiling for $1 \mathrm{~min}$. The LPS extraction obtained was subjected to SDS-PAGE to confirm that no protein was present in the extracted LPS.

\section{Experimental Design in Mouse Model}

All mice included in the current study were approximately of the same age and strain. Sixty healthy Balb c mice were placed in twelve plastic cages each one containing five mice. The mice were divided into three major groups (A, B and C). Group A is the control group $(\mathrm{n}=10)$ and these were inoculated with $0.4 \mathrm{ml}$ of PBS pH 7.4 orally. The treatment groups $(\mathrm{B} ; \mathrm{n}=25$ and $\mathrm{C} ; \mathrm{n}$ =25) were inoculated with P. multocida type B: 2 and lipopolysaccharide respectively. The mice in group B and $\mathrm{C}$ were further divided into five subgroups. The subgroups were designated based on the graded doses as $\mathrm{B} 10^{1}-\mathrm{B} 10^{9}$ for Pasteurella multocida and $\mathrm{C} 10^{1}-\mathrm{C} 10^{9}$ for LPS respectively. The mice were observed for $120 \mathrm{~h}$ post-inoculation, clinical signs and mortality rates were observed. Mice showed severe clinical signs and survived mice after $120 \mathrm{~h}$ post-inoculation were sacrificed via cervical dislocation approach and postmortem examination was performed. All procedures and experiments illustrated were undertaken under a project license approved by Animal Utilization Protocol Committee, Faculty of veterinary medicine, Universiti Putra Malaysia, with the reference number: UPM/IACUC/AUP-R017/2014.

\section{Analysis of Cytokines}

Interleukin-1 (IL-1 $\beta$ ) and Interleukin-6 (IL-6) were determined from serum using high sensitivity and specificity (Cusabio ${ }^{\circledR}$, Wuhan, China PR) mice IL-1 $\beta$ and IL-6 ELISA kits in accordance to the manufacturer's specifications and protocol.

\section{Statistical Analysis}

All the data were analyzed using JMP® 9. NC: SAS Institute Inc. software Version. The data were considered significant at $\mathrm{p}<0.05$.

\section{Results}

The concentration of IL-1 $\beta$ was $1.45 \mathrm{ng} \mathrm{mL}-1$ and significantly higher $(\mathrm{p}<0.001)$ in the $\mathrm{B} 10^{7}$ of $P$. multocida type B: 2 and $0.81 \mathrm{ng} \mathrm{mL}^{-1}$ in $\mathrm{C} 10^{9}$ of LPS compared to the control group and the other treatment groups. The concentration of IL- 6 was $0.16 \mathrm{ng} \mathrm{mL}^{-1}$ and significantly higher $(\mathrm{p}<0.001)$ in the $\mathrm{B} 10^{3}$ of $P$. multocida type B: 2 and $0.14 \mathrm{ng} \mathrm{mL}^{-1}$ in $\mathrm{C} 10^{9}$ of LPS compared to the control group and the other treatment groups (Fig. 1-4).

\section{Discussion}

Haemorrhagic Septicaemia (HS) is ranked as the primary fatal disease in water buffaloes and is a cause 
of major economic losses in cattle and water buffalo in Asian countries. The current understandings on bacterial interaction with the host suggest that $P$. multocida establishes a complex interaction in host tissues and utilizes available niches effectively to grow rapidly and cause diseases at favourable circumstances (Khaleel et al., 2013). The mechanisms of acute disease pathogenesis and role of bacterial, LPS or host factors that induce pathology and the nature of the immune response to Pasteurella multocida are poorly understood. The present study investigated the role of the whole cell of Pasteurella multocida and its surface component (LPS) inoculated orally to observe the changes in pro-inflammatory cytokines (IL-1 $\beta$ and IL-6) using mice as an experimental animal model in vivo.
The results of the present study describe infection of mice with the wild type $P$. multocida strain B: 2 and its LPS via oral route of inoculation in different doses of $\left(10^{1}, 10^{3}, 10^{5}, 10^{7}\right.$ and $\left.10^{9}\right)$ cfu respectively. Jesse et al. (2013a; 2013b; 2013c) inoculated Pasteurella multocida via different routes to elicit infections in the animal models suitably. Similarly, in the present study graded doses of Pasteurella multocida and its LPS elicit immune responses in mice as a result of the infections. If the infection is to result in disease, the pathogen might also release toxins or toxic by-products, or interact with the host immune system (Harper et al., 2011). The findings of (Harper et al., 2011 ) is in agreement to the findings of the present study in which the inoculation of the bacterial LPS induces significant alterations in the concentrations of IL- $1 \beta$ and IL- 6 as a result of graded doses of $\left(10^{1}\right.$, $10^{3}, 10^{5}, 10^{7}$ and $\left.10^{9}\right)$ cfu respectively.

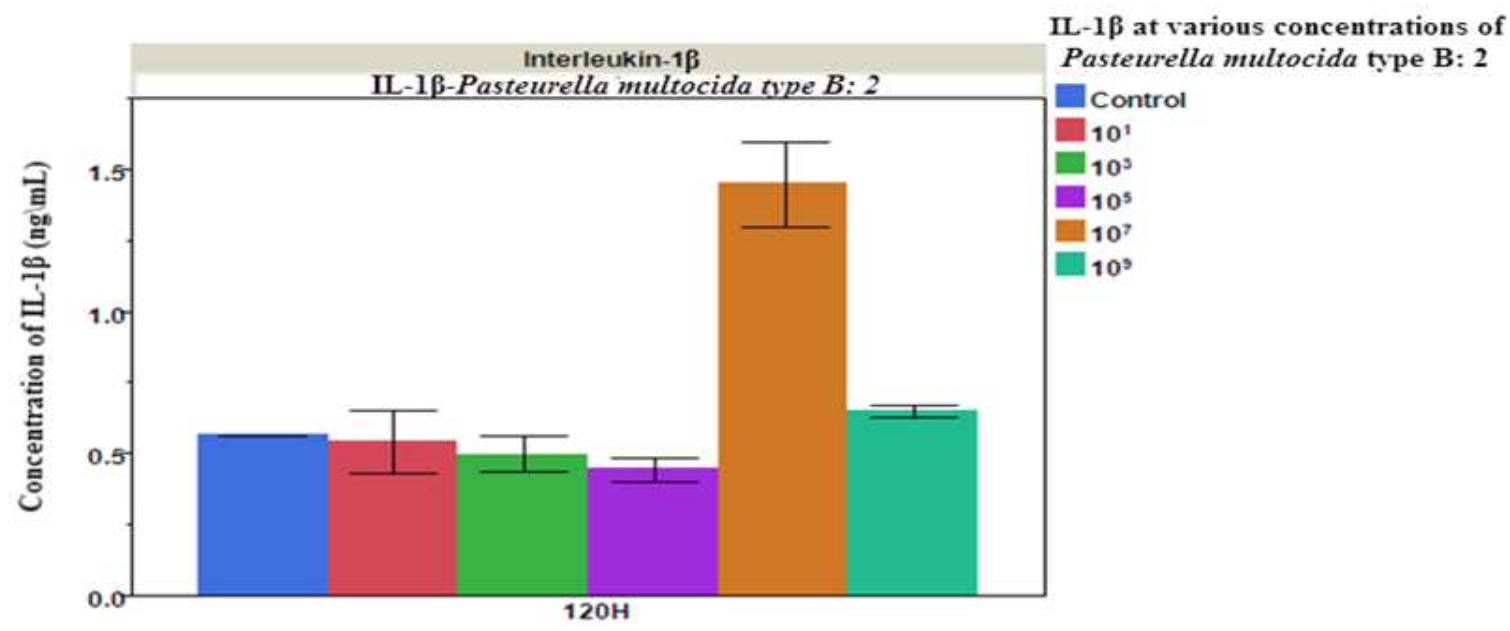

Post inoculation Time with Pasteurella multocida type B: 2

Fig. 1. Various concentrations of IL-1 $\beta$ via oral inoculation with Pasteurella multocida type B: 2

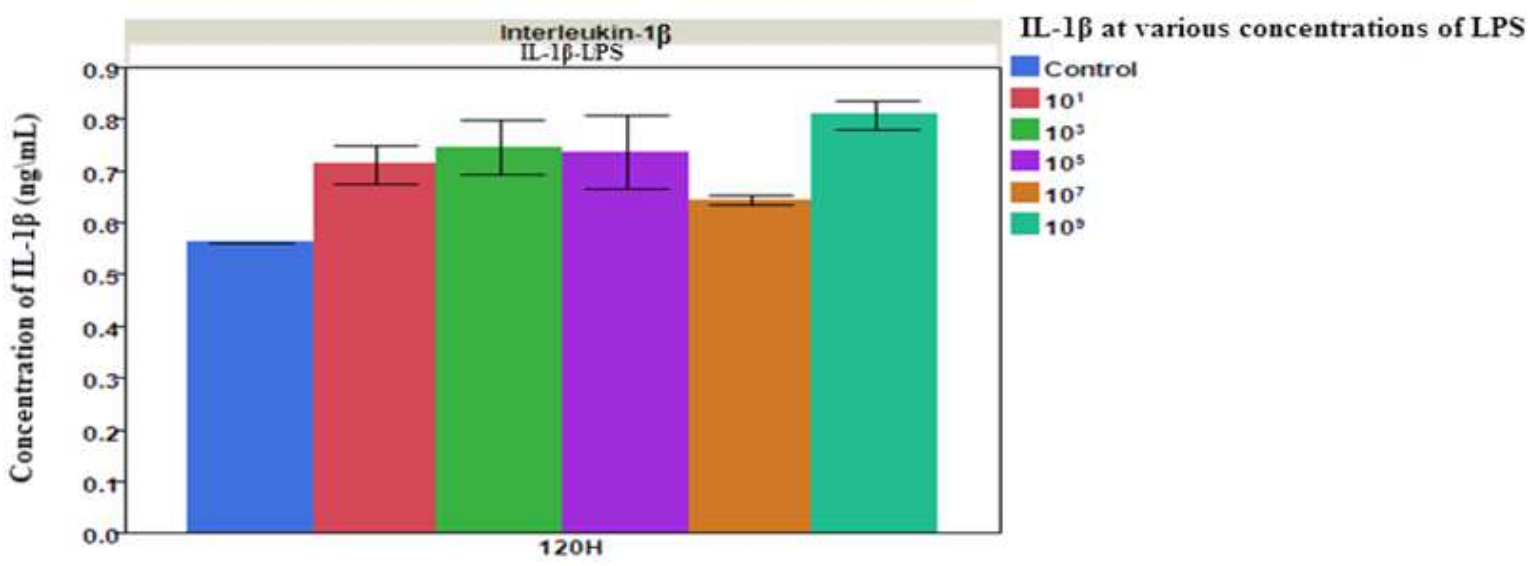

Post inoculation Time with LPS

Fig. 2. Various concentrations of IL-1 $\beta$ via oral inoculaton of LPS 


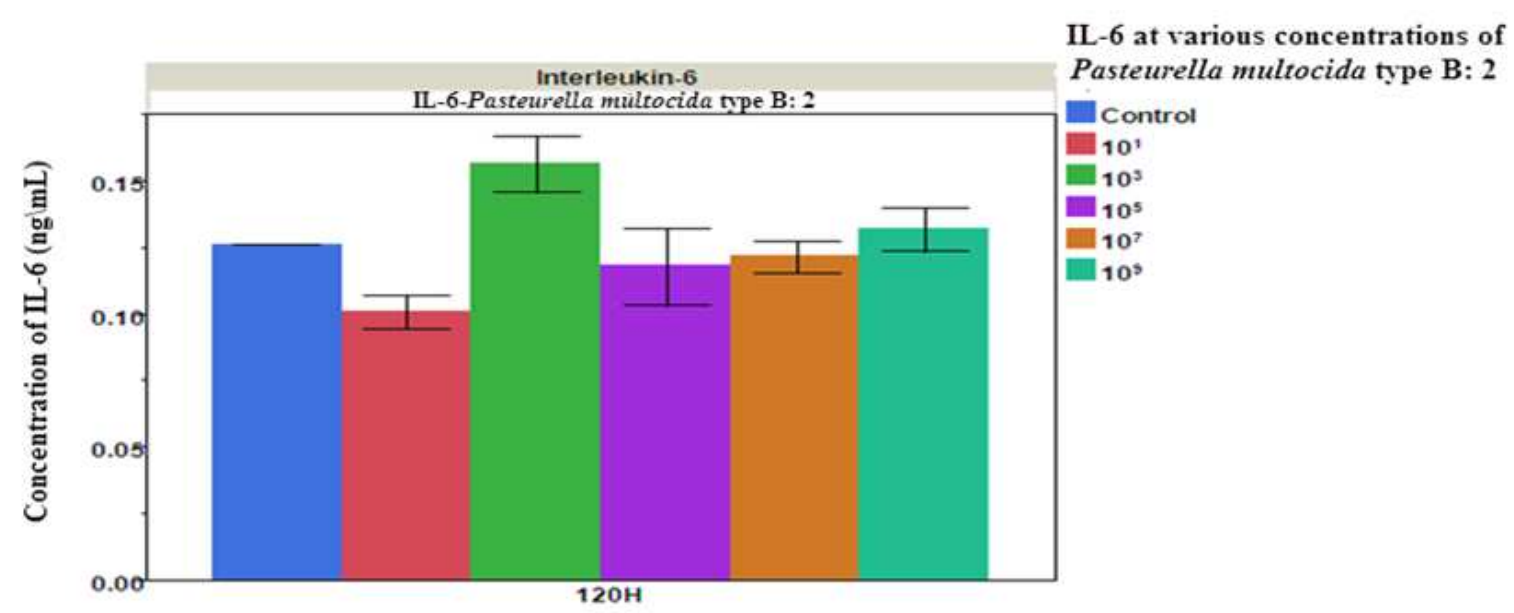

Post inoculation Time with Pasteurella multocida type B: 2

Fig. 3. Various concentrations of IL-6 via oral inoculation with Pasteurella multocida type B: 2

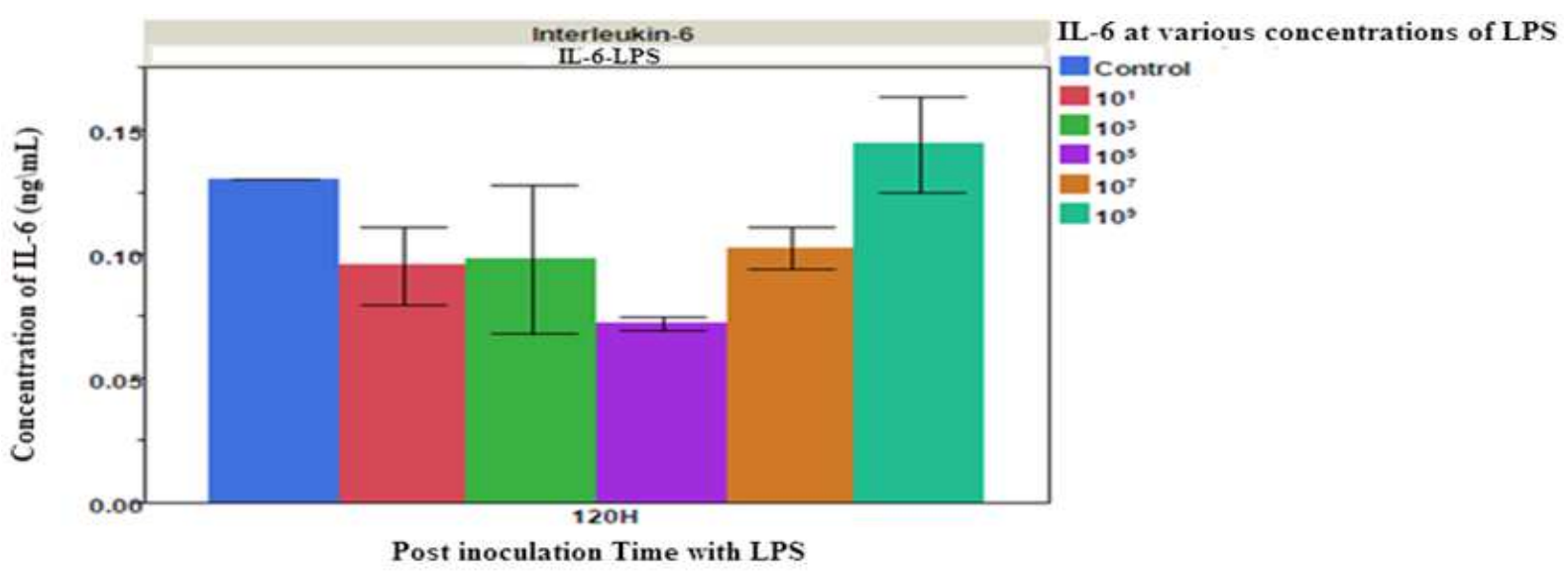

Fig. 4. Various concentrations of IL-6 via oral inoculation with LPS

In this study it seems that all the treatment groups of mice which were inoculated orally with Pasteurella multocida and its LPS have the same spectrum of activity in the production of acute infection of HS with significant increase in the concentration of inflammation cytokine (IL-1 $\beta$ and IL-6) in the serum. This result agree with other researchers findings in the previous studies, Khaleel et al. (2013) showed in his study in which he challenge BALB/c mice intraperitoneally with as few as $20 \mathrm{cfu}$ of $P$. multocida to produce an overwhelming septicaemia in mice within $30 \mathrm{~h}$ of post-inoculation. In the same manner (Jesse et al., 2013b) produce clinico-pathological responses in calves inoculated with Pasteurella multocida and its LPS via the intramuscular and intravenous routes. Following infection, with Pasteurella multocidaat a dose rate of $1 \mathrm{~mL}$ of $10^{9} \mathrm{cfu}$ in a study conducted by Abdullah et al. (2013a) two out 16 mice died per-acutely within $24 \mathrm{~h}$ while 10 died in a similar manner within $48 \mathrm{~h}$. In the present study, after $120 \mathrm{~h}$ of post inoculation with graded doses of $0.4 \mathrm{~mL}$ of Pasteurella multocida and its LPS no death was recorded. This could be due to the protracted time period and lower dosage of $0.4 \mathrm{~mL}$ of $10^{1}, 10^{3}, 10^{5}, 10^{7}$ and $10^{9}$ cfu of Pasteurella multocida and its LPS respectively for the onset of infections to occur via the oral route.

Treatment groups of mice which were inoculated via oral routes with LPS showed high concentration of IL-1 $\beta$ compared with groups of mice inoculated with Pasteurella multocida and control group at $120 \mathrm{~h}$ of post-inoculation. This result may be due to the route of inoculation and the potential doses used of Pasteurella multocida and its LPS. Furthermore, in different study by (Dionissopoulos et al., 2012) found that there were increases in the concentration of IL-1 $\beta$ associated with 
pathogenesis of lung injury in bovine pneumonic pasteurellosis which significantly increased the levels of IL-1 $\beta$ within the pneumonic lesions and in bronchoalveolar lavage cells from $P$. haemolytica infected calves and similar results were observed in the present study and those of (Praveena et al., 2010) in mice infected with Pasteurella multocida serotype A: 1. This increase in IL-1 $\beta$ in our work could be due to the effect of LPS which was inoculated orally into the mice producing the same effect of orally inoculated whole cell of $P$. multocida type B: 2 which induce HS symptoms leading to enhance immune defense to secrete high concentration of IL-1 $\beta$. Previous works widely showed that Lipopolysaccharide (LPS) and outer membrane proteins of gram negative bacteria play a dominant role during the host immune response (Harper et al., 2011). The LPS of P. multocida has endotoxic properties, particularly in buffalo, where the injection of purified LPS from a serogroup B strain was able to mimic the clinical signs of bovine haemorrhagic septicaemia (Jesse et al., 2013b; 2013c). There were increases in the concentration of IL- 6 with $0.4 \mathrm{~mL}$ of $10^{3}$ cfu in the mice that were inoculated orally with Pasteurella multocida type B: 2 compared with those inoculated with LPS and the control group. Schmidt et al. (2014) observed that single intravenous injection of LPS was tolerated easily by mice without any observable pathology or evidence of ill health. They also stated that repeated intraperitoneal injections of LPS in mice at $8 \mathrm{~h}$ intervals caused the mice to become ill (Schmidt et al., 2014) exhibiting reduced social and feeding activity, huddling behavior with piloerection and shivering, increased skin turgor and weight loss and eventually led to hypothermia before the mice became moribund. However, Pasteurella multocida type B: 2 exert its effect at a concentration higher with respect to LPS and the induction starts later and lasts longer. Active concentration of both Pasteurella multocida and its LPS can frequently be reached at infection sites either from gram-negative bacteria outer membrane blebbing (LPS) or bacterial lysis as in consequence of host defence (Harper et al., 2011). LPS and Pasteurella multocida may initiate interaction with host cells either by adherence, either by engaging a cascade of secondary molecules that have abilities to affect host defense systems. In a study conducted by (Zhao et al., 2009) in mice infected with Pasteurella multocida showed significantly enhanced immunity in the mice to the bacteria vaccine, which increased IL-6 in the blood of mice. This study is similar to the current study in which IL-6 was found to increase post inoculation with Pasteurella multocida via the oral route compared to those mice infected with LPS and PBS orally. However, IL-6 level was found to be higher in the treatment group of mice which were inoculated with Pasteurella multocidawith $0.4 \mathrm{~mL}$ of $10^{3} \mathrm{cfu}$ compare with treatment group of mice inoculated with LPS with $0.4 \mathrm{~mL}$ of $10^{9} \mathrm{cfu}$ which increased after $120 \mathrm{~h}$ post-inoculation. It has been reported that IL- 6 regulates the transition from neutrophil to monocyte recruitment during inflammatory process (Praveena et al., 2010). This could be due to the increased concentration of $P$. multocida which was inoculated orally. Pro-inflammatory mediators and especially (IL-1 $\beta$ and IL-6) were reported to enhance leukocyte transmigration into the site of infection by favouring expression of cell adhesion molecules and production of eicosanoids and prostaglandins that perpetuate the inflammatory cascade in septicemia (Praveena et al., 2010). The higher levels of (IL-1 $\beta$ and IL-6) cytokines in the mice serum in this research work could also be attributed to fever, anorexia and behavioural changes observed in the infected animals (Dionissopoulos et al., 2012; Gyenai et al., 2012; Schmidt et al., 2014). The increased in serum cytokine levels of pro-inflammatory cytokines (IL-1 $\beta$ and IL-6) at $120 \mathrm{~h}$ post-inoculation could perchance be due to the damage of the tissue cells and infiltration of inflammatory cells into the sites of infections. The increase in the secretion of IL- $1 \beta$ and IL- 6 was detected in the serum of the mice in the treatment groups which were inoculated orally with different doses of LPS. It is possible that the dose of LPS inoculated was sufficient to produce its endotoxic effects to alter the pro-inflammatory cytokines (IL-1 $\beta$ and IL-6) in mice inoculated orally. A one dose inoculation of LPS through oral route produces the proinflammatory cytokines (IL-1 $\beta$ and IL-6) in the blood that mimic a response more closely associated with clinical septicaemia. The previous studies were similar to the current study where there was an evident increase in the concentration of pro-inflammatory cytokines (IL-1 $\beta$ and IL-6) via oral inoculation of $P$. multocida and its lipopolysaccharide using graded doses.

\section{Conclusion}

In the current study, serum concentrations of proinflammatory cytokines (IL-1 $\beta$ and IL-6) were affected by the graded doses of $P$. multocida and its polysaccharide and caused HS in the treatment groups of mice. The severity of host cell response differs between each group. The immunogen group of mice showed changes in pro-inflammatory cytokines (IL-1 $\beta$ and IL-6) concentrations. The present study showed significant differences in the levels of the pro-inflammatory cytokines (IL-1 $\beta$ and IL-6) in mice experimentally 
infected with Pasteurella multocida and its lipopolysaccharide. It is assumed that these differences in serum concentrations of pro-inflammatory cytokines (IL-1 $\beta$ and IL-6) in the present study were mainly due to the graded doses of $10^{1}, 10^{3}, 10^{5}, 10^{7}$ and $10^{9} \mathrm{cfu}$ of Pasteurella multocida and its LPS respectively. In conclusion, this result showed the potential effect of the graded doses of LPS and Pasteurella multocida which enhanced the immune responses in the animal models thereby increasing the production of different types of pro-inflammatory cytokines particularly IL$1 \beta$ and IL- 6 in the serum of the mice. Therefore, it is concluded that these quantitative indicators (IL-1 $\beta$ and IL-6) can be used as a potential biomarkers for detection of HS in susceptible animals.

\section{Acknowledgement}

We thank the staff of the Department of Veterinary Clinical Studies, Universiti Putra Malaysia and Research Centre for Ruminant Disease, in particular Yap Keng Chee, Mohd Jefri Norsidin and Mohd Fahmi Mashuri for their assistance. The project was funded by Ministry of Higher Education Malaysia.

\section{Author's Contributions}

All authors equally contributed in this work.

\section{Ethics}

This article is original and contains unpublished materials. The corresponding author confirms that all of the other authors have read and approved the manuscript and no ethical issues involved.

\section{References}

Abdullah, F.F.J., A.Y. Osman, L. Adamu, M.S.M. Yusof and A.R. Omar et al., 2013a. Polymerase Chain reaction detection of Pasteurella multocida Type $\mathrm{B}: 2$ in mice following oral inoculation. Asian J. Anim. Vet. Adv., 8: 493-501. DOI: 10.3923/ajava.2013.493.501

Abdullah, F.F.J., M.M. Khaleel, L. Adamu, A.Y. Osman and A.W. Haron et al., 2013b. Polymerase chain reaction detection of Pasteurella multocida type B:2 in mice following oral inoculation. Asian J. Anim. Vet. Adv., 8: 493-501. DOI: 10.3923/ajava.2013.493.501

Abubakar, M.S. and M. Zamri-Saad, 2011. Clinicopathological changes in buffalo calves following oral exposure to B: 2. Basic Applied Pathol., 4: 130-135.

DOI: $10.1111 / \mathrm{j} .1755-9294.2011 .01113$
Affandi, A.S., J.F.F. Abdullah, A.A. Saharee and J. Sabri, 2012. Clinical response and pathological changes associated with Pasteurella multocida type B: 2 infections through oral route inoculation in mice. Proceedings of the 7th Seminar of Veterinary Sciences, Feb. 2-Mar. 2, University Putra Malaysia.

Ataei, S.R., J.C. Burchmore, A. Hodgson, R. Finucane and J.G. Coate, 2009. Identification of immunogenic proteins associated with protection against haemorrhagic septicaemia after vaccination of calves with a live-attenuated araA derivative of Pasteurella multocida B: 2. Res. Vet. Sci., 87: 207-210. DOI: 10.1016/j.rvsc.2009.01.007

Boyce, J.D., M. Harper, I.W. Wilkie and B. Adler, 2010. Pasteurella. In: Pathogenesis of Bacterial Infections in Animals, Gyles, C.L., J.F. Prescott, G. Songer and C.O. Thoen (Eds.), Wiley-Blackwell, Ames, ISBN-10: 0813812372, pp: 664-664.

Dinarello, C.A., 2009. Immunological and inflammatory functions of the interleukin-1 family. Annu. Rev. Immunol., 27: 519-550.

DOI: 10.1146/annurev.immunol.021908.132612

Dionissopoulos, L., M.A. Steele, O. AlZahal, J.C. Plaizier and S. Li et al., 2011. Subacute Ruminal Acidosis (SARA) in dairy cows leads to increases in ruminal Lipopolysaccharide (LPS), plasma LPS binding protein and correlates with the rumen epithelial interleukin-6 (IL-6) response. Canad. J. Anim. Sci., 91: 503-503.

Faez, F.J., S.A. Affandi, A.Y. Osman, L. Adamu and M. Zamri-Saad et al., 2013. Clinico-pathological features in mice following oral exposure to Pasteurella multocida type B: 2. J. Agric. Vet. Sci., 3: 35-39. DOI: 10.9790/23800343539

Gyenai, K., N. Mikiashvili, H. Ismail and M. Worku, 2012. Influence of heirloom tomato polyphenol extracts on expression of inflammation genes in bovine. Am. J. Anim. Vet. Sci., 7: 126-135. DOI: 10.3844/ajavsp.2012.126.135

Harper, M., A.D. Cox, B. Adler and J.D. Boyce, 2011. Pasteurella multocida lipopolysaccharide: The long and the short of it. Vet. Microbiol., 153: 109-115. DOI: $10.1016 /$ j.vetmic.2011.05.022

Hawari, A.D., M. Obeidat, S.S. Awaisheh, H.I. AlDaghistani and A.A. Al-Abbadi et al., 2014. Prevalence of mastitis pathogens and their resistance against antimicrobial agents in Awassi sheep in Albalqa province of Jordan. Am. J. Anim. Vet. Sci., 9: 116-121. DOI: 10.3844/ajavsp.2014.116.121

Jamal, H., M.H.M. Nazmul, N. Masyitah, A.A. Mahmood and S. Ismail, 2013. Alternative animal model for pasteurella multocida and Haemorrhagic septicemia. Biomed. Res., 24: 263-266. 
Jesse, F.F.A., L. Adamu, Y.O. Abdinasir, M.Z. Saad and Z. Zakaria et al., 2013a. Acute phase protein profiles and clinico-pathological changes in mice associated with the infection of Pasteurella multocida type B and the bacterial lipopolysaccharide and outer membrane protein immunogens. J. Anim. Vet. Adv., 12: 186-193.

Jesse, F.F.A., L. Adamu, Y.O. Abdinasir, Z. Zakaria and R. Abdullah et al., 2013b. Clinico-pathological responses of calves associated with infection of Pasteurella multocida type B and the bacterial Lipopolysaccharide and outer membrane protein immunogens. Int. J. Anim. Vet. Adv., 5: 190-198.

Jesse, F.F.A., L. Adamu, Y.O. Abdinasir, Z. Zakaria and R. Abdullah et al., 2013c. Acute phase protein profile in calves following infection with whole cell, lipopolysaccharide and outer membrane protein extracted from Pasteurella multocida type B: 2. Am. J. Anim. Vet. Adv., 8: 655-662. DOI: 10.3923 /ajava.2013.655.662

Khaleel, M.M., F.F.J. Abdullah, L. Adamu, A.Y. Osman and A.W. Haron et al., 2013. Acute phase protein responses in mice infected with river water contaminated by Pasteurella multocida type B: 2 . Am. J. Anim. Vet. Sci., 8: 159-164. DOI: 10.3844 /ajavsp.2013.159.164

Kharb, S. and S. Charan, 2013. Mouse model of haemorrhagic septicaemia: Dissemination and multiplication of Pasteurella multocida B: 2 in vital organs after intranasal and subcutaneous challenge in mice. Vet. Res. Commun., 37: 59-63. DOI: $10.1007 / \mathrm{s} 11259-012-9547-5$

Moffatt, J.H., M. Harper, P. Harrison, J.D.F. Hale and J.D. Boyce et al., 2010. Colistin resistance in Acinetobacter baumannii is mediated by complete loss of lipopolysaccharide production. Antimicrob. Agents Chemother., 54: 4971-4977. DOI: $10.1128 /$ AAC.00834-10
Monisha, B. and M. Saxena, 2012. Interleukin-1 (IL1) family of cytokines: Role in Type 2 Diabetes. Clin. Chim. Acta, 413: 1163-1170.

DOI: $10.1016 /$ j.cca.2012.03.021

Praveena, P.E., S. Periasamy, A.A. Kumar and N. Singh, 2010. Cytokine profiles, apoptosis and pathology of experimental Pasteurella multocida serotype A1 infection in mice. Res. Vet. Sci., 89: 332-339. DOI: 10.1016/j.rvsc.2010.04.012

Rania, K.D., D.I. Ramadan, A.M. Mohy, H.A. Raafat and S.M. El-Kateb et al., 2014. Interleukin-1 $\beta$ gene polymorphisms in Egyptian patients with rheumatoid arthritis. Comparative Clin. Pathol., 23: 689-694. DOI: 10.1007/s00580-012-1672-6

Schmidt, M., C. Ammon, P.C. Schon, C. Manteuffel and G. Hoffmann, 2014. The suitability of infrared temperature measurements for continuous temperature monitoring in gilts. Arch Tierz, 57: 1-12. DOI: 10.7482/0003-9438-57-021

Shafarin, M.S., M. Zamri-Saad, B.S. Khairani and A.A. Saharee, 2009. Pathological changes in the respiratory tract of goats infected by Pasteurella multocida B: 2. J. Camp. Path, 140: 194-197. DOI: $10.1016 /$ j.jcpa.2008.10.005

Zhao, Z.Z., H.B. Zhang, Q. Chen, D. Su and R. Gao et al., 2009. Promotion of immunity of mice to Pasteurella multocida and hog cholera vaccine by pig interleukin6 gene and $\mathrm{CpG}$ motifs. Comparative Immunol. Microbiol. Infect. Dis., 32: 191-205.

DOI: 10.1016/j.cimid.2007.10.001 